Original Research Paper

\title{
Statistical Measurement of Nurses' Level of Awareness of Value of Occupational Therapy Services in a Paediatric Ward
}

\author{
${ }^{1}$ Lesetja Given Ledwaba, ${ }^{1}$ Legashe Hezekiel Ledwaba, ${ }^{1}$ Rirhandzu Valley Mathebula, ${ }^{1}$ Monica Magole \\ Makgale, ${ }^{1}$ Lerato Ammilorate Malele, ${ }^{1}$ Tshinetise Alfred Ramukumba and ${ }^{2}$ Solly Matshonisa Seeletse \\ ${ }^{I}$ Department of Occupational Therapy, \\ Sefako Makgatho Health Sciences University, MEDUNSA, 0204, Gauteng Province, South Africa \\ ${ }^{2}$ Department of Statistics and Operations Research, \\ Sefako Makgatho Health Sciences University, MEDUNSA, 0204, Gauteng Province, South Africa
}

Article history

Received: 01-08-2016

Revised: 01-12-2016

Accepted: 30-03-2017

Corresponding Author: Solly Matshonisa Seeletse Department of Statistics and Operations Research, Sefako Makgatho Health Sciences University, MEDUNSA, 0204, Gauteng Province, South Africa Email: solly.seeletse@smu.ac.za

\begin{abstract}
The study investigated the extent of information the nurses have about Occupational Therapy (OT) and its place within a health Multidisciplinary Team (MDT). It took place in the paediatric ward of the Dr George Mukhari Academic Hospital in Gauteng Department of Health. It was stimulated by the adverse attitude of the nurses to the OT staff and/or students from Sefako Makgatho Health Sciences University (SMU) for prescribed OT activities in that ward. The purpose of the study was to demonstrate that if nurses in a MDT setting did not understand OT purpose, then this may cause lack of their appreciation of OT activities and of occupational therapists. Forty-three nurses participated in the study. Most of them did not know much about OT and seemed to have different impressions about the OT profession. The study recommended that the nurses should be informed about other practitioners in the MDT of their workplace, how each one works and the scope of the nurses' work.
\end{abstract}

Keywords: Multidisciplinary Team, Occupational Therapy Intervention, Paediatric Ward

\section{Introduction}

Understanding the role of each member in the MDT in the workplace is crucial. According to Athal and Caldwell (2006), working in a MDT requires many skills, which involves appreciating own role and other professionals' roles. In a health facility specifically, it is vital for the benefit of the patients in health facilities to ensure that appropriate referrals are made to specific MDT members. This could improve the well-being of patients, thus enhancing the morbidity rate reduction. Occupational Therapy (OT) services optimize the level of independence in all areas of occupations (Duncan, 2012). OT services aim to empower occupationally dysfunctional clients to discharge their everyday personal management, work and recreational activities at their highest levels of independency. It aims to restore dignity and self-respect, improve quality of life, improve health, manage illness, develop skills, recover and maintain a healthy life style, among others. OT enhances independency in the patients' lives. Patel (2005) confirmed these facts with paediatrics and recommended OT in an interdisciplinary team approach to the treatment of children with cerebral palsy. However, Bodenheimer and Smith (2013) observed that occupational therapists are highly skilled professionals but who are not recognised as competent contributors in the MDT.

The OT study at the SMU consists of researchers' clinical blocks the students have to attend as part of their course. During these blocks, there was a difference in the functioning between the cerebral palsied children who started receiving OT services at an early stage and those who did not receive OT services at an early stage. There was also a sign of differences between the children who stopped the intervention and the ones who continued receiving OT services. There was deterioration in functioning in those who stopped OT services. From this observation, Patel's (2005) findings were confirmed. Hashem and Khawla (2011) found that only $40 \%$ of physicians and $48 \%$ of nurses in Jordan stated that they had adequate information about OT and the services of occupational therapists. Conversely, $76 \%$ of the physical therapists stated that they had adequate information about OT. A problem of nurses in the paediatric ward of the Dr George Mukhari Academic Hospital (DGMAH) 
in South Africa is to believe that they can do all OT activities required in the ward, including those for which they were not trained to do.

The nurses in DGMAH showed inadequate information about the OT profession. This claim is based on their comments that OT is only to exercise patients, keep them busy when they are bored and entertain them while still in hospital. Nursing staff seemed to believe that OT has no therapeutic value other than keeping the children busy as occupational therapists in paediatric wards use play as a method of intervention. Therefore, this study aimed to determine the knowledge of nursing staff on the OT services in the paediatric wards at DGMAH.

\section{Roles of OT in Paediatrics}

Patel (2005) explained the occupational therapists work with children with cerebral palsy in improving fine motor abilities. One example was the use of upper limbs to perform daily activities. OT effectively improves and maintains adaptive fine motor activities of children with cerebral palsy. Also, OT boosts MDT and the efficiency of services rendered by occupational therapists. Case-Smith and O'Brien (2010) explains that OT's role in paediatrics is to develop an intervention by analysing the child's behaviour and performance. Occupational therapists evaluate the child's performance in relation to the environmental support, looking at the discrepancies between the child's performances, activity demand and interpret the meaning and importance of the discrepancy.

\section{Benefits of OT Intervention}

Case-Smith and O'Brien (2010) show that school based OT intervention focuses on the child's educational goals and can support academic goals (e.g., handwriting and literacy) or functional goals (e.g., manipulating and organising materials). Therapeutic play offers a practical vehicle to enlist a child's attention, to practice specific motor and functional skills, to help sensory processing, perceptual abilities and cognitive development. In therapeutic settings, play often becomes a tool to work for a goal. Despite the fact that it is goal-oriented, externally controlled aspects of the therapy situations conflict with the essence of play itself. OT intervention provides a full rehabilitation program and also supports the child's efforts within the academic environment. Solomon and O'Brien (2011) agree that OT benefits to the child's early school years in a school. The treated child can participate effectively and actively in classroom, self-care, peer socialization, leisure, vocational, educational and community activities.

\section{MDT Approach}

Bos and Vaughn (1991) explain the importance of a team of professionals working obligingly with teachers to develop successful programs and strategies in the classroom for learners with special needs. The team can consist of the principal, class teachers, occupational therapist, psychologist, nurse, physiotherapist, speech and language pathologist and social worker. A study conducted in two public schools in Ontario on teachers' knowledge of the role and effectiveness of OT in schools showed that all the teachers in the schools valued the work of occupational therapists (Fairbairn and Davidson, 1993). However, the teachers also expressed confusion over the roles of occupational therapists. They disagreed with occupational therapists about some of the roles. They also wanted occupational therapists to develop a greater awareness of the educational system's needs. According to Koch et al. (2009), fruitful rehabilitation depends on well organised collaboration from different disciplines, where each discipline understands and recognizes the role of other members. Unfortunately, several studies reported the lack of knowledge among health care professionals on different aspects of the OT profession. They lacked knowledge about occupational therapists' contributions to patient care, areas of practice, the OT process and intervention techniques and media (Kraus, 2002; Patel and Shriber, 2000; Pottebaum and Svinarich, 2005).

An interdisciplinary team should be involved in all procedures and protocol related to the treatment of the child with psychosocial disorders (Rutter and Taylor, 2005). The OT services are needed to form the team in order to maximize the patients' functional level. Casteleijn and Graham (2012) say that in a mental health care setting, the OT professionals struggle to convince other professions about their contribution because common OT services look simple since they involve making cards, facilitating groups, preparing and cooking meal with the patients and so on. However, occupational therapists are actually applying their professional skills and clinical reasoning in planning and implementing the interventions. Nevertheless, the anecdotal feedback from individual clients, their families and other team members confirms the value of OT. As Bodenheimer and Smith (2013) noted, practitioners such as occupational therapists are highly skilled professionals utterly underused in their capacity to fill roles of physicians or physical extenders. Hammill and Pearson (2011) believe that the best way to promote the OT profession is networking it with inter professionals. The multidisciplinary approach is necessary in the paediatric field. Hammill and Pearson (2011) state that children with developmental problems are assessed by members of anMDT. With parental involvement, the team formulates an individual programme of care and support to meet the child's needs. Nurses, physiotherapists, occupational therapists, speech therapists, psychologists and the specialist doctors could form an ideal team (Hammill and Pearson, 2011). 


\section{Importance of the Study}

This research has potential to identify challenges of occupational therapists in wards from the nurses' attitudes and understanding of other roles to help patients.

\section{Methodology}

\section{Design}

The study was exploratory and descriptive study, focusing on exploring knowledge of nursing staff about the OT services in the paediatric ward at DGMAH. It used quantitative survey data to obtain characteristics, attitudes and previous experiences (Leedy and Ormrod, 2013).

\section{Population and Sample}

The study population consisted of all the professional nurses working in the paediatric wards at DGMAC in 2015. Leedy and Ormrod $(2005 ; 2013)$ guide that for a small population $(\mathrm{N}<100)$, census (i.e. the entire population) should be selected. The nurses' population of the study was 45 . Only the willing and available ones were included in the study.

\section{Instruments and Data}

A questionnaire divided into three sections was used to collect data. Section A had questions on 'understanding of OT services'; section B focused on 'awareness of OT services offered in the paediatric wards'; and section C focused on 'value of OT in the MDT'. The questionnaire was piloted (Ruxton and Colegrave, 2006) using five (5) professional nurses in a DGMAH wards apart from the paediatric ward. After piloting the questionnaire was finalized and then selfadministered to the respondents. Computer spreadsheets were used in data handling. Data analysis consisted on descriptive statistics, percentages and graphical displays.

\section{Results}

\section{Participants}

Forty-three nurses responded. Their frequencies are:

\section{Experiences}

The total 115 (in bold) is based on all 43 original values, but changes when outliers are removed.

\section{Detecting Outliers}

Small and large outliers can be identified using lower and upper bounds. Let $Q_{1}$ and $Q_{3}$ be first and third quartiles in the data. Let $k$ be a constant normally chosen as either 1.5 or 3 . According to Dovoedo (2011), outliers are values outside the lower and upper limits:

$$
L=Q_{1}-k\left(Q_{3}-Q_{1}\right)
$$

$$
U=Q_{3}+k\left(Q_{3}-Q_{1}\right)
$$

Therefore, with $k=3, Q_{1}=1, Q_{1}=4$, we have $L=-1$ and $U=8$. No small outlier appears in Table 1, but the upper outlier exists.

The outliers of years of experience $(26,30,31)$ were identified. A mini-analysis below shows the impact of outliers.

Comparing the first two tables, the outliers affect 11 of the 14 (about $79 \%$ ) of the descriptive statistics. Some of these measures are affected to as large as $95 \%$. In the next discussions, outliers are removed to safeguard the truthfulness of the study results. The analyses are based on 41 respondents.

The total 28 has shrunk from 115 (Table 1) when the three outliers have been removed and now 43 values are left. (Both 28 and 40 are in bold).

The analyses show that the average experiences of the teachers who responded was about 4.7 years with outlying one and about 2.8 years after removing the outliers. The modal and median ages were three (3) years in both cases. This shows that with outliers, skewness to the right was shown while after removing the outliers, approximate normality was achieved. This justifies maintaining the removal of outliers.

\section{Level of Education}

For the respondents' level of education let 'Educ $=$ level of education', ' $\mathrm{B}=$ bachelor's degree', 'Hons = honors bachelor's', 'M = master's' degrees. The observations were:

Figure 1 shows that all the respondents were graduates. Most had bachelor's degrees. They were over five times of those with bachelor's honors degrees. The fewest had master's degrees as no one had a doctoral degree. Thus, as the degrees advanced, there were fewer respondents holding them.

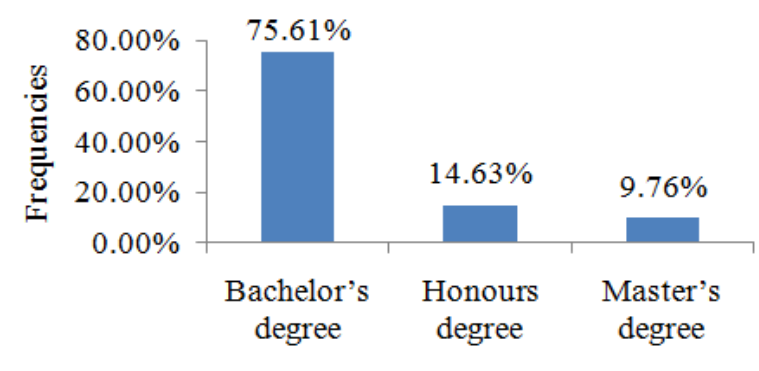

Highest qualifications held

Fig. 1. Levels of education

Table 1. Years of experience with outliers

\begin{tabular}{lllllllllllll}
\hline $\operatorname{Exp}^{*}$ & 0 & 1 & 2 & 3 & 4 & 5 & 6 & 7 & 26 & 30 & 31 & 115 \\
\hline$f$ & 2 & 4 & 12 & 13 & 3 & 4 & 0 & 2 & 1 & 1 & 1 & 43 \\
\hline *Exp =
\end{tabular}


Table 1 contains undesirable outlying values with their impact displayed in Table 2. The resulting Table 3 after removing these outliers is used for all the analyses. Table 4 displays the qualifications and Table 5 shows that workplaces of the respondents. Most had bachelor's degrees. Also, most wore employed in public hospitals.

Table 6 describes the way the nurses understand occupational therapy. Table 7a contains Table 6 where it is indicate as 'observed'. The other section consists of derived values corresponding to those of Table 6 when the assumption of independence between employ and response is made. It is the hypothesis being tested. The values in Table $7 \mathrm{~b}$ are derived for Equation 2.

Table 8 explains the nurses' awareness of services of occupational therapists. Table $9 \mathrm{a}$ are values based on the hypothesis of independence between nurses and response items. Table $9 \mathrm{~b}$ are values based on Equation 2.

Table 10 are nurses' perceived worth of occupational therapists in MDT settings. Table 11a are values based on the hypothesis of independence between nurses and response items. Table $11 \mathrm{~b}$ are values for Equation 2.

Table 12 explains the combined items of nurses describing OT issues. Table 13a are values based on the hypothesis of independence between nurses and response items. Table 13b are values for Equation 2.

The calculations for each test appears in its section.

\section{Places where Respondents had Worked}

The frequency total of 55 exceeds the number 41 of respondents because some respondents had in previously worked in other workplaces. Most respondents (73\%) had worked in the public hospital private hospitals. The clinics followed, but with a much lower extent $(20 \%)$ compared to those with public hospital experiences. The fewest (7\%) were those who had worked in private hospitals.

\section{Nurses' Understanding of OT}

On this topic let, $\mathrm{SA}=$ strongly agree, $\mathrm{A}=$ disagree, $\mathrm{N}=$ undecided, $\mathrm{D}=$ disagree, $\mathrm{SD}=$ strongly disagree and define the items as follows:

- $\quad$ ' 1 ' = I have enough information about OT services

- $\quad$ ' 2 ' = OT forms part of the MDT

- 3 ' $=$ OT differs from physiotherapy profession in terms of treatment methods

- $\quad$ ' 4 ' = Everyone wanting to be OT-pist must obtain a university degree

- $\quad 5$ ' = OT facilitates functional independence

The positive skewness shape of the graph indicated that most respondents agreed with the given statements. The hypothesis being tested was whether the response give was independent of the item of the respondents' perception. In determining if it fitted the proportions, a goodness-of-fit test using chi-square is appropriate
(Wackerly et al., 2009). The null hypothesis being tested and the alternative hypothesis are given by:

$H_{0}$ : Respondents' understanding of OT and their responses are independent

$H_{a}$ : Respondents' understanding of OT and their responses are not independent

Let $o_{i}$ denote the $i^{\text {th }}$ observed frequencies and $e_{i}$ the corresponding expected frequencies in a contingency table (e.g., frequency table). The value of the test statistic (Bless et al., 2006) is given by the formula:

$\chi^{2}=\sum_{i=1}^{k} \frac{\left(o_{i}-e_{i}\right)^{2}}{e_{i}}$

On small observed frequencies (less than 5), Simon (2002) recommends use of the Yates corrected chisquare equation given as:

$\chi^{2}=\sum_{i=1}^{k} \frac{\left(\left|o_{i}-e_{i}\right|-0.5\right)^{2}}{e_{i}}$

In both versions the chi-square statistics' degrees of freedom (d.f.) is $\mathrm{k}-1$ when the number of categories $\mathrm{k}$ is used (Curwin and Slater, 2002); or $(c-1)(r-1)$ when the contingency table if a matrix with cbeing the number of columns and $r$, the number of rows, is used (Tabachnick and Fidell, 2007). Also, the rule is to reject the null hypothesis if the calculated test statistic exceeds the critical value obtained from the table of chi-square statistics. The observed frequencies and the expected frequencies are presented together.

Since some observed values are lower than 5, Equation 2 is used to calculate the value of the test statistic. The chi-square values are.

The value of the chi-square statistic is:

$$
\chi^{2}=\sum_{i=1}^{k} \frac{\left(\left|o_{i}-e_{i}\right|-0.5\right)^{2}}{e_{i}}=28.3260
$$

The value of the d.f. $=(c-1)(r-1)=(5-1)(5-1)=$ $(4)(4)=16$. Thus, from Kutner et al. (2005), the critical value at $5 \%$ level of significance with 16 d.f. is $\chi_{0.05}^{2}=26.2962$. The test statistic exceeds the critical value.

Hence, the hypothesis of independence should be rejected. This implies that there is no enough statistical evidence at the $5 \%$ significance level that the respondents' understanding of OT and their responses are independent.

This provides some indication that the nurses' responses were based on some understanding of the roles of occupational therapists. 


\section{Nurses' Awareness of OT Services}

Define the items as follows:

- $' 1$ ' = occupational therapists use play as therapy in treating children

- 2 ' $'=$ they use splints to treat musculaoskeletal conditions in children

- ' 3 ' = they prescribe wheelchairs or buggies for paediatric patients

- ' ' 4 ' = they adapt toys and the environment for children with disabilities

- $\quad$ ' 5 ' = they do proper positioning to treat children

The table of responses is:

Chi-square test of independence:

$H_{0}$ : Respondents' responses and the awareness items are independent

$H_{a}$ : Respondents' responses and the awareness items are not independent

The value of the chi-square statistic is:

$$
\chi^{2}=\sum_{i=1}^{k} \frac{\left(\left|o_{i}-e_{i}\right|-0.5\right)^{2}}{e_{i}}=15.4557
$$

Table 2. Years of experiences descriptive statistics

\begin{tabular}{llll}
\hline Statistic & $\begin{array}{l}\text { With } \\
\text { outliers }\end{array}$ & $\begin{array}{l}\text { Without } \\
\text { outliers }\end{array}$ & $\begin{array}{l}\text { Outlier } \\
\text { impact }\end{array}$ \\
\hline Mean & 4.65116 & 2.825 & $39.3 \%$ \\
Standard error & 1.05805 & 0.24778 & $76.6 \%$ \\
Median & 3 & 3 & $9.0 \%$ \\
Mode & 3 & 3 & $77.4 \%$ \\
Standard deviation & 6.93811 & 1.56709 & $94.9 \%$ \\
Sample variance & 48.1373 & 2.45577 & $88.7 \%$ \\
Kurtosis & 9.87198 & 1.11984 & $75.2 \%$ \\
Skewness & 3.26424 & 0.81003 & $77.4 \%$ \\
Range & 31 & 7 & $0.0 \%$ \\
Minimum & 0 & 0 & $77.4 \%$ \\
Maximum & 31 & 7 & $310 \%$ \\
Sum & 115 & 28 & $7.0 \%$ \\
Count & 43 & 40 & $76.6 \%$ \\
Confidence level (95\%) & 2.13523 & 0.50118 & \\
\hline
\end{tabular}

Table 3. Years of experiences without outliers

\begin{tabular}{llllllllll}
\hline Exp* $^{*}$ & 0 & 1 & 2 & 3 & 4 & 5 & 6 & 7 & 28 \\
\hline
\end{tabular}

Table 4. Level of qualification

\begin{tabular}{lllll}
\hline Educ & B & Hons & M & Total \\
\hline$f$ & 31 & 6 & 4 & 41 \\
\hline
\end{tabular}

Table 5. Workplaces experienced by respondents

\begin{tabular}{lllll}
\hline Work & Clinic & $\begin{array}{l}\text { Public } \\
\text { hospital }\end{array}$ & $\begin{array}{l}\text { Private } \\
\text { hospital }\end{array}$ & Total \\
\hline$f$ & 11 & 40 & 4 & 55 \\
\hline
\end{tabular}

Table 6. The way respondents construe OT

\begin{tabular}{lllllll}
\hline & SA & A & N & D & SD & Total \\
\hline '1' & 6 & 25 & 6 & 3 & 1 & 41 \\
'2' & 23 & 18 & 0 & 0 & 0 & 41 \\
'3' & 21 & 18 & 1 & 0 & 1 & 41 \\
'4' & 22 & 10 & 6 & 1 & 2 & 41 \\
'5' & 14 & 15 & 8 & 2 & 1 & 41 \\
\hline
\end{tabular}

Table 7a. Observed Vs expected responses

\begin{tabular}{|c|c|c|c|c|c|c|c|c|c|}
\hline \multicolumn{5}{|c|}{ Observed } & \multicolumn{5}{|c|}{ Expected } \\
\hline SA & A & $\mathrm{N}$ & $\mathrm{D}$ & SD & SA & A & $\mathrm{N}$ & D & SD \\
\hline 6 & 25 & 6 & 3 & 1 & 17.2 & 17.2 & 4.2 & 1.2 & 1 \\
\hline 23 & 18 & 0 & 0 & 0 & 17.2 & 17.2 & 4.2 & 1.2 & 1 \\
\hline 21 & 18 & 1 & 0 & 1 & 17.2 & 17.2 & 4.2 & 1.2 & 1 \\
\hline 22 & 10 & 6 & 1 & 2 & 17.2 & 17.2 & 4.2 & 1.2 & 1 \\
\hline 14 & 15 & 8 & 2 & 1 & 17.2 & 17.2 & 4.2 & 1.2 & 1 \\
\hline
\end{tabular}

Table 7 b. $\quad \chi^{2}=\sum_{i=1}^{k} \frac{\left(\left|o_{i}-e_{i}\right|-0.5\right)^{2}}{e_{i}}$

\begin{tabular}{lllll}
\hline 6.6564 & 3.0983 & 0.4024 & 1.4083 & 0.2500 \\
1.6331 & 0.0052 & 3.2595 & 0.4083 & 0.2500 \\
0.6331 & 0.0052 & 1.7357 & 0.4083 & 0.2500 \\
1.0750 & 2.6099 & 0.4024 & 0.0750 & 0.2500 \\
0.4238 & 0.1680 & 2.5929 & 0.0750 & 0.2500 \\
\hline
\end{tabular}

Table 8. Respondents' awareness of OT services

\begin{tabular}{lllllll}
\hline & SA & A & N & D & SD & Total \\
\hline ' 1 ' & 25 & 14 & 0 & 2 & 0 & 41 \\
'2' & 13 & 19 & 4 & 2 & 3 & 41 \\
'3' & 23 & 10 & 5 & 2 & 1 & 41 \\
'4' & 24 & 15 & 1 & 1 & 0 & 41 \\
'5' & 18 & 20 & 1 & 1 & 1 & 41 \\
\hline
\end{tabular}

Table 9a. Observed Vs expected responses

\begin{tabular}{llllllllll}
\hline \multicolumn{3}{l}{ Observed } & \multicolumn{1}{l}{ Expected } \\
\hline------- & & & & & \\
SA & A & N & D & SD & SA & A & N & D & SD \\
\hline 25 & 14 & 0 & 2 & 0 & 20.6 & 15.6 & 2.2 & 1.6 & 1 \\
13 & 19 & 4 & 2 & 3 & 20.6 & 15.6 & 2.2 & 1.6 & 1 \\
23 & 10 & 5 & 2 & 1 & 20.6 & 15.6 & 2.2 & 1.6 & 1 \\
24 & 15 & 1 & 1 & 0 & 20.6 & 15.6 & 2.2 & 1.6 & 1 \\
18 & 20 & 1 & 1 & 1 & 20.6 & 15.6 & 2.2 & 1.6 & 1 \\
\hline
\end{tabular}

\begin{tabular}{llrll} 
Table 9b. $\chi^{2}=\sum_{i=1}^{k} \frac{\left(\left|o_{i}-e_{i}\right|-0.5\right)^{2}}{e_{i}}$ & & \\
\hline 0.7383 & 0.0776 & 1.3136 & 0.0063 & 0.2500 \\
2.4471 & 0.5391 & 0.7682 & 0.0063 & 0.2500 \\
0.1752 & 1.6673 & 2.4045 & 0.0063 & 0.2500 \\
0.4083 & 0.0006 & 0.2227 & 0.0063 & 0.2500 \\
0.2141 & 0.975 & 0.2227 & 0.0063 & 0.2500 \\
\hline
\end{tabular}

Table 10. Perceived value of OT services in the MDT

\begin{tabular}{lllllll}
\hline & SA & A & N & D & SD & Total \\
\hline '1' & 24 & 10 & 2 & 4 & 1 & 41 \\
'2' & 15 & 21 & 2 & 2 & 1 & 41 \\
'3' & 15 & 19 & 5 & 2 & 0 & 41 \\
'4' & 15 & 19 & 5 & 1 & 1 & 41 \\
'5' & 23 & 18 & 0 & 0 & 0 & 41 \\
\hline
\end{tabular}




\begin{tabular}{|c|c|c|c|c|c|c|c|c|c|}
\hline \multicolumn{5}{|c|}{ Observed } & \multicolumn{5}{|c|}{ Expected } \\
\hline SA & A & $\mathrm{N}$ & $\mathrm{D}$ & SD & SA & A & $\mathrm{N}$ & $\mathrm{D}$ & SD \\
\hline 24 & 10 & 2 & 4 & 1 & 18.4 & 17.4 & 2.8 & 1.8 & 0.6 \\
\hline 15 & 21 & 2 & 2 & 1 & 18.4 & 17.4 & 2.8 & 1.8 & 0.6 \\
\hline 15 & 19 & 5 & 2 & 0 & 18.4 & 17.4 & 2.8 & 1.8 & 0.6 \\
\hline 15 & 19 & 5 & 1 & 1 & 18.4 & 17.4 & 2.8 & 1.8 & 0.6 \\
\hline 23 & 18 & 0 & 0 & 0 & 18.4 & 17.4 & 2.8 & 1.8 & 0.6 \\
\hline
\end{tabular}

\begin{tabular}{lcccc} 
Table 11b. $\chi^{2}=\sum_{i=1}^{k} \frac{\left(\left|o_{i}-e_{i}\right|-0.5\right)^{2}}{e_{i}}$ & & \\
\hline 1.4136 & 2.7362 & 0.0321 & 1.6056 & 0.0167 \\
0.4571 & 0.5523 & 0.0321 & 0.0500 & 0.0167 \\
0.4571 & 0.0695 & 1.0321 & 0.0500 & 0.0167 \\
0.4571 & 0.0695 & 1.0321 & 0.0500 & 0.0167 \\
0.9136 & 0.0006 & 1.8893 & 0.9389 & 0.0167 \\
\hline
\end{tabular}

Table 12. Responses on accumulated OT study items

\begin{tabular}{lllllll}
\hline & SA & A & N & D & SD & Total \\
\hline A. & 86 & 86 & 21 & 6 & 5 & 210 \\
B. & 103 & 78 & 11 & 8 & 5 & 210 \\
C. & 92 & 87 & 14 & 9 & 3 & 210 \\
\hline
\end{tabular}

Table 13. Observed Vs expected responses

\begin{tabular}{|c|c|c|c|c|c|c|c|c|c|}
\hline \multicolumn{5}{|c|}{ Observed } & \multicolumn{5}{|c|}{ Expected } \\
\hline SA & A & $\mathrm{N}$ & $\mathrm{D}$ & SD & SA & A & $\mathrm{N}$ & D & SD \\
\hline 86 & 86 & 21 & 6 & 5 & 93.7 & 83.7 & 15.3 & 7.7 & 4.3 \\
\hline 103 & 78 & 11 & 8 & 5 & 93.7 & 83.7 & 15.3 & 7.7 & 4.3 \\
\hline 92 & 87 & 14 & 9 & 3 & 93.7 & 83.7 & 15.3 & 7.7 & 4.3 \\
\hline
\end{tabular}

Table 13b. $\chi^{2}=\sum_{i=1}^{k} \frac{\left(\left|o_{i}-e_{i}\right|-0.5\right)^{2}}{e_{i}}$

\begin{tabular}{lllll}
\hline 0.5483 & 0.0402 & 1.7409 & 0.1775 & 0.0064 \\
0.8330 & 0.3191 & 0.9583 & 0.0036 & 0.0064 \\
0.0145 & 0.0959 & 0.0453 & 0.0906 & 0.1603 \\
\hline
\end{tabular}

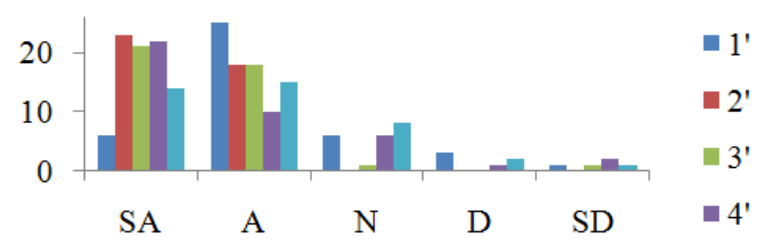

Fig. 2. Respondents' interpretation of OT

Figure 2 shows that these nurses have no high regard for occupational therapy. In Fig. 3 the nurses seem to lack awareness of OT role. Figure 4 shows nurse to lack an understanding of OT in multidisciplinary healthcare. In Fig. 4 they are shown to lack an understanding of OT value. Figure 5 shows that on aggregate, nurses are clueless about OT. The figures follow below.

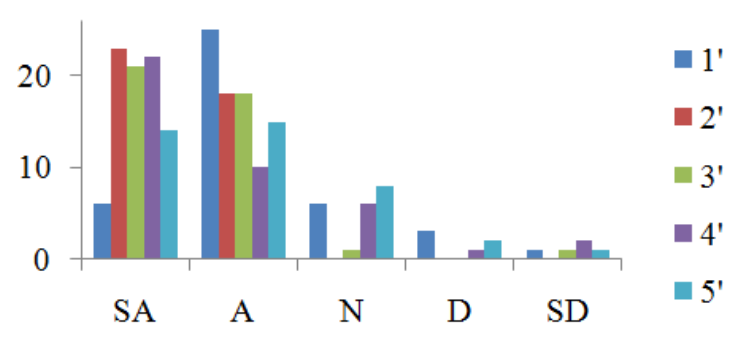

Fig. 3. Respondents' interpretation of OT

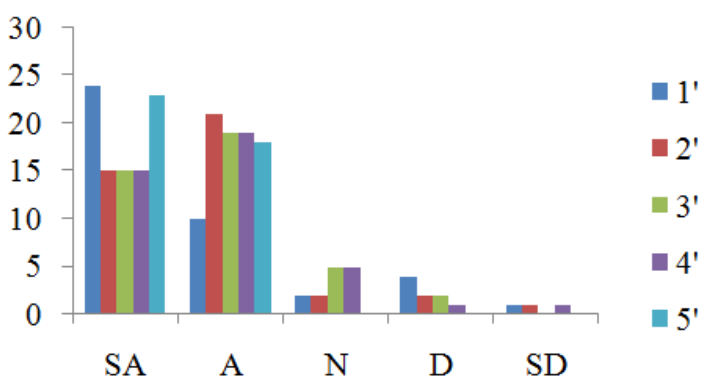

Fig. 4. Perceived value of OT services in the MDT

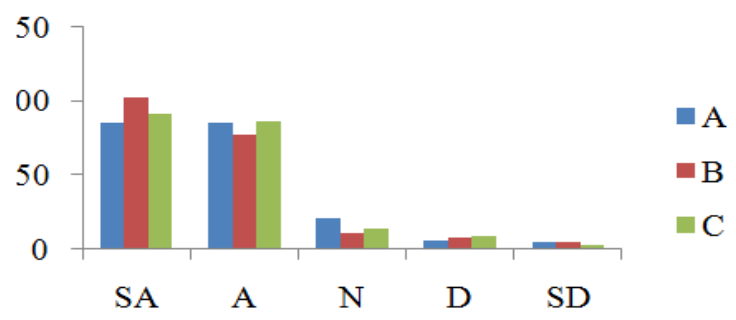

Fig. 5. Responses on accumulated OT study items

The d.f. $=16$. Thus, the critical value at $5 \%$ level of significance is $\chi_{0.05}^{2}=26.2962$. The test statistic does not exceed the critical value and the hypothesis of independence cannot be rejected. This implies that there is enough statistical evidence at the $5 \%$ significance level to believe that the respondents' understanding of OT and the awareness responses are independent.

\section{Perceived value of OT in MDT}

Define the items as follows:

- ' 1 ' = occupational therapists service has an effect on the patients' health and well-being

- ' 2 ' = I am convinced of the importance of OT service to the patients

- 3 ' 3 occupational therapists should get referrals from other team members in order to improve functionality of the patients

- ' 4 ' = nurses should assist in implementing OT programs in the wards

- ${ }^{\prime} 5$ ' = OT service should be integrated with other team members' intervention 
The table of responses is:

Chi-square test of independence:

$H_{0}$ : Respondents' perceived OT importance in MDT and perception items are independent

$H_{a}$ : Respondents' perceived OT importance in MDT and perception items are not independent

The value of the chi-square statistic is:

$\chi^{2}=\sum_{i=1}^{k} \frac{\left(\left|o_{i}-e_{i}\right|-0.5\right)^{2}}{e_{i}}=13.9222$

The d.f. $=16$. Thus, the critical value at $5 \%$ level of significance is $\chi_{0.05}^{2}=26.2962$. The test statistic does not exceed the critical value. Then the hypothesis of independence cannot be rejected. This implies that there is enough statistical evidence at the $5 \%$ significance level to believe that the respondents' perceived OT importance in MDT and perceptions are independent.

\section{Statistical Comparison of Accumulated Items}

This section combines the responses from each section and names it with the main issue of the section. A graphical display shows the comparison of these items. Then the main issues and the responses are tested for independence. Define the items as:

$\mathrm{A}=$ Understanding about OT

$\mathrm{B}=$ Awareness of OT services

$\mathrm{C}=$ Perceived Value of OT in MDT

The skewness to the right is an indication that most respondents were agreeing with the given statements.

Chi-square test of independence:

$H_{0}$ : Responses and the accumulated OT items are independent

$H_{a}$ : Responses and the accumulated OT items are not independent

The value of the chi-square statistic is:

$\chi^{2}=\sum_{i=1}^{k} \frac{\left(\left|o_{i}-e_{i}\right|-0.5\right)^{2}}{e_{i}}=5.0405$

The d.f. $=(c-1)(r-1)=(3-1)(5-1)(2)(4)=8$. Thus, the critical value at $5 \%$ level of significance is $\chi_{0.05}^{2}=15.5073$. The test statistic does not exceed the critical value. Then the hypothesis of independence cannot be rejected. This implies that there is enough statistical evidence at the $5 \%$ significance level to believe that the responses on accumulated OT items are independent.

\section{Discussion}

The outlier experiences showed that only a tiny minority of nurses were experienced. Most were not too experienced since the dominant experiences were three and then two years. None of these nurses was under qualified. They were dominated by the graduates with bachelor's degree. They were becoming much fewer as the degrees advanced. Notwithstanding these high qualifications, no one had a doctoral degree. Also, even with the negative impressions, nurses still showed willingness to assist in implementing OT services. They also did not have problems with OT's incorporation within the MDT.

Many nurses seemed to have lacked an understanding of OT. They also seemed to lack an appreciation of OT as an MDT component. The employees did not know how OT differed with physiotherapy. Also, they did not believe it was necessary for occupational therapist to obtain degree qualifications for their practice. They could also not imagine occupational therapy functioning independently. These contradictions showed that the nurses did not know OT and its role in the workplace.

The nurses indicated that they knew that play and use of toys could be used for therapy in treating children. They also stated that they knew that splints were useful to treat musculoskeletal conditions; that they knew that occupational therapists could prescribe wheelchairs; and that they knew that occupational therapists could do positioning in children's treatment.

\section{Perceived Value of OT in MDT}

The nurses believed that OT services could improve patients' health and well-being. They were convinced that OT services were helpful to patients. Most nurses thought they could assist in implementing OT programmes and wanted OT services to be integrated with other team members' interventions.

\section{Statistical Comparison of Accumulated Items}

When accumulated, the nurses were overwhelmingly did not understand OT, lacked awareness of OT services and did not perceive OT services as being valuable.

\section{Recommendations and Conclusion}

\section{Conclusion}

The nurses did not seem to know much about the occupational therapy profession and its roles within a multidisciplinary team. Also, when they came into contact with occupational therapists, they did not appreciate the occupational therapy work. The study justified the negative attitudes of nurses towards occupational therapy and occupational therapists. It 
showed that the nurses lacked knowledge and understanding of occupational therapy.

\section{Recommendation}

The nurses should be:

- Enlightened about other professionals in the health system, particularly in the workplace

- Informed about the roles of other professionals in their workplace

- $\quad$ Trained and conditioned to participate within a MDT

\section{Acknowledgement}

The authors are grateful to the respondents and data collectors in the study who are anonymous.

\section{Funding Information}

The research project was financially supported by the Occupational Therapy Department, Sefako Makgatho Health Sciences University.

\section{Author's Contribution}

Lesetja Given Ledwaba: Was the foremost coordinator of the project team and liaison with the statistician.

Legashe Hezekiel Ledwaba, Rirhandzu Valley Mathebula, Monica Magole Makgale and Lerato Ammilorate Malele: Were team members on the project. They performed the tasks that include data collection, data organisation, searching and presenting literature topics as and when guided by the study supervisor.

Tshinetise Alfred Ramukumba: Supervised the study. He guided the project team on research methods and on selecting the study topic.

Solly Matshonisa Seeletse: Analysed the data and also developed this manuscripts.

\section{Ethics}

There will not be ethical issues beyond publications of this paper as all the protocols had been observed prior to submitting this paper to AJAS.

\section{References}

Athal, A. and K. Caldwell, 2006. Nurses' perceptions of multidisciplinary team work in acute health-care. Int. J. Nurs. Pract., 12: 359-395.

DOI: $10.1111 / \mathrm{j} .1440-172 X .2006 .00595 . \mathrm{X}$

Bless, C., C. Higson-Smith and A. Kagee, 2006. Fundamentals of Social Research Methods: An African Perspective. 1st Edn., Juta and Company Ltd, Cape Town, ISBN-10: 0702171948, pp: 190.
Bodenheimer, T.S. and M.D. Smith, 2013. Primary care: Proposed solutions to the physician shortage without training more physicians. Health Affairs, 32: 1881-1886. PMID: 24191075

Bos, S.C. and S. Vaughn, 1991. Strategies for Teaching Students with Learning and Behavior Problems. 2nd Edn., Allyn and Bacon, Boston, ISBN-10: 0205129706, pp: 475.

Case-Smith, J. and J.C. O'Brien, 2010. Occupational Therapy for Children. 6th Edn., Mosby/Elsevier, Maryland Heights, ISBN-10: 032305658X, pp: 857.

Casteleijn, D. and M. Graham, 2012. Domains for occupational therapy outcomes in mental health practices. South African J. Occupat. Therapy, 42: 26-30.

Curwin, J. and R. Slater, 2002. Quantitative Methods for Business Decisions. 1st Edn., Cengage Learning EMEA, London, ISBN-10: 1844805743, pp: 790.

Dovoedo, Y.H., 2011. Contributions to outlier detection methods: Some theory and applications. PhD Thesis, University of Alabama, Tuscaloosa, USA.

Duncan, E., 2012. Foundations for Practice in Occupational Therapy. $5^{\text {th }}$ Edn., Churchill Livingstone/Elsevier, Edinburgh, ISBN-10: 0702053120, pp: 282.

Fairbairn, M. and I. Davidson, 1993. Teachers' perceptions of the role of occupational therapist in schools. Canad. J. Occupat. Therapy, 60: 185-191. DOI: $10.1080 / 19411243.2016 .1183158$

Hammill, D.D. and N.A. Pearson, 2011. Developmental Test of Visual Perception-2. 1st Edn., Pro-Ed, San Antonio.

Hashem, S.A.T. and A. Khawla, 2011. Health professionals' knowledge of occupational therapy in Jordan. Occupat. Therapy Health Care, 26: 74-87. PMID: 23899109

Koch, L., D. Glitchel and K. Higgins, 2009. Preparing students to be empathic interdisciplinary rehabilitation team members. Rehabilitat. Educ., 23: 119-126. DOI: 10.1891/088970109805059182

Kraus, E., 2002. How valued is occupational therapy? A survey of general practitioners. Ergotherapy Rehabilitat., 41: 21-28.

Kutner, M.H., C.J. Nasctsheim, J. Neter and W. Li, 2005. Applied Linear Statistical Models. 5th Edn., McGrawHill Irwin, Boston, Mass, ISBN-10: 0071122214, pp: 1396.

Leedy, P.D. and J.E. Ormrod, 2005. Practical Research: Planning a' nd Design. 10th Edn., Prentice Hall, Upper Saddle River, ISBN-10: 0131247204, pp: 319.

Leedy, P.D. and J.E. Ormrod, 2013. Practical Research: Planning and Design. 10th Edn., Pearson Education, Harlow, ISBN-10: 1292021179, pp: 384.

Patel, A. and L. Shriber, 2000. Nurse practitioners' knowledge of occupational therapy. Occupat. Therapy Health Care, 13: 53-71. PMID: 23931671 
Patel, D.R., 2005. Therapeutic interventions in cerebral palsy. Ind. J. Pediatr., 72: 979-983. PMID: 16391455

Pottebaum, J. and A. Svinarich, 2005. Psychiatrists' perceptions of occupational therapy. Occupat. Therapy Mental Health, 21: 1-12.

DOI: $10.1300 / J 004 v 21 n 01 \_01$

Rutter, M. and E. Taylor, 2005. Child and Adolescent Psychiatry. In: Occupational Therapy in Psychiatry and Mental Health, Crouch, R. and V. Alers (Eds.), Wiley, London, ISBN-10: 1861564201, pp: 638.

Ruxton, G.T. and N. Colegrave, 2006. Experimental Design for the Life Sciences. 2nd Edn., Oxford University Press, Oxford, ISBN-10: 019928511X, pp: 162.
Simon, M.K., 2002. Probability Distributions Involving Gaussian Random Variables: A Handbook for Engineers and Scientists. Springer Science and Business Media, New York, ISBN-10: 0387476946, pp: 200.

Solomon, J.W. and C. O'Brien, 2011. Pediatric Skills for Occupational Therapy Assistants. 3rd Edn., Elsevier/Mosby, St. Louis, Mo., ISBN-10: 0323059104, pp: 630.

Tabachnick, B.G. and L.S. Fidell, 2007. Using Multivariate Statistics. 5th Edn., Pearson, Boston, ISBN-10: 0205465250, pp: 980.

Wackerly, D., W. Mendenhall and R.L. Scheaffer, 2009. Mathematical Statistics with Applications. 7th Edn., Academic Press, Amsterdam, ISBN-10: 0080951708, pp: 848 . 